\title{
From Discursive Practice to Logic? Remarks on Logical Expressivism
}

\author{
Rodger Kibble \\ Department of Computing, \\ Goldsmiths, University of London
}

R.KIBBLE@GOLD.AC.UK

Editor: Jonathan Ginzburg

Submitted 11/2017; Accepted 08/2020; Published online 08/2020

\begin{abstract}
This paper proposes a novel account of the conditional locution as grounded in practices of goaldirected cooperative dialogue. It is argued that a conditional semantics can be obtained within a language fragment that lacks this locution, but supports assertive, inferential and directive practices. We take Brandom's logical expressivist programme as a point of departure, but argue that this programme is empirically flawed as it underestimates the pervasive context-dependence of linguistic items including logical vocabulary. We further take issue with his claim that a discursive practice involving only assertion and inference is sufficient for the conservative introduction and deployment of conditional vocabulary. A more promising route is provided by the introduction of directives, as in so-called "pseudo-imperatives" such as Get individuals to invest their time and the funding will follow: this has a conditional sense that if individuals invest their time, then funding will follow. We propose a semantic analysis for these forms which builds on Kukla and Lance's account of prescriptives, and argue that our analysis more faithfully captures the "irrealis" nature of conditionals. The analysis is presented in terms of an information-state based dialogue model, with the information state comprising a partitioned commitment store. It is argued that our "dialogical" analysis of conditional reasoning is faithful to Brandom's Sellarsian intuition of linguistic practice as a game of giving and asking for reasons. We conclude by contextualising and situating Brandom's programme against the larger field of practice theory, by means of a comparison with the works of sociologist, anthropologist and philosopher Pierre Bourdieu, and suggest that this comparison reveals further challenges to the expressivist programme. We also take note of Narasimhan et al's recent proposals for agent-based modelling of social practice theory as a possible basis for future development.
\end{abstract}

Keywords: dialogue, inference, commitments, conditionals, logical expressivism, Brandom, Bourdieu, Wittgenstein, information state, social practice theory

\section{Introduction}

This paper combines a critical appraisal of Robert Brandom's notion of discursive practice and in particular his programme of logical expressivism with a novel conjectural account of the genesis of the conditional locution. The constructive proposal departs in many ways from Brandom's account but shares an objective of developing an account of linguistic meaning which is "firmly rooted in actual practices of producing and consuming speech acts" (MIE $\left.{ }^{1}\right)$. To be clear from the start, the analysis involves a conception of meaning in terms of social relations between interlocutors rather

1. The remainder of this paper adopts established abbreviations MIE for Brandom (1994), AR for Brandom (2000), BSD for Brandom (2000). 
than their mental states and intentions. This approach is in sympathy with Bender and Koller's position that meaning does not inhere in distributional facts alone, as seems to be claimed by much of the literature on neural language models, but takes a different stance from their assumption that meaning is "the relation between a linguistic form and communicative intent" (Bender and Koller, 2020, p. 5185). Brandom (1983; 1994; 2000; 2008) sets out to show:

1. how one can develop such an account without presupposing semantic or intentional concepts;

2. in particular, how formal logic can be shown to supervene on everyday linguistic practice.

We begin by attempting to sketch out some essential concerns of Brandom's programme, according to which utterances are acts in a social space which bring about alterations in the normative status of dialogue participants. Brandom's ambitious programme ${ }^{2}$, most fully set out in MIE, starts from a pragmatist, Wittgensteinian approach to language use involving practices such as assertion, inference, and the assessment of normative statuses of discourse participants including committment or entitlement to making propositional claims. In this framework, the essential import of an assertion is that the speaker both takes on a social commitment to justify its content, and claims entitlement to this commitment. Entitlement may be claimed by such means as producing evidence for the assertion, or deferring to the testimony of another speaker. Interlocutors are taken to maintain deontic scoreboards which keep track of these statuses. On this view, assertion is not a purely monological practice but is ineluctably situated within a context of social interaction. The notion of practice plays an important part, and one goal of this paper is to try to make clear what is meant by a (discursive) practice. Practice theory is a loosely defined approach in the humanities and social sciences which takes "practices" as an appropriate level of granularity for scholarly study rather than e.g. rules, concepts, conventions or statistical regularities. Joseph Rouse (2007a) gives a useful survey of this field, discussing the "range and scope of activities taken by various theorists to constitute "practices": a minimal definition might class practices as stereotyped patterns of sequences of meaningful performances. Rouse classes Brandom as a practice theorist who treats "language itself (or 'discursive practices') as a paradigmatic application of practice talk". In the final section of this paper we will attempt to situate Brandom within this larger field by means of a detailed comparision with the work of Pierre Bourdieu $(1977 ; 1991)$ and tentatively consider how this work may be operationalised using agent-based models (Narasimhan et al., 2017). Brandom's inferentialism was worked out in confrontation with the then dominant frameworks of formal semantics, and is largely intended to tackle the kind of problems formal semanticists thought were important. The important new paradigm of distributional semantics (DS, Boleda and Herbelot (2016)), like Brandom's inferentialism, has also been claimed to be inspired by Wittgenstein ${ }^{3}$, though is arguably at odds with Brandom's reading of the Philosophical Investigations (Wittgenstein, 2009) which argues against identifying linguistic or social norms with statistical regularities. The practice-based approach is intended as an alternative both to formal, rule-based accounts and "regularist" statistical analysis.

2. Tutorial presentations such as (Wanderer, 2008; Turbanti, 2017; Loeffler, 2018) generally treat MIE, AR and BSD as making up a unitary body of work, though Brandom's Introduction to BSD makes clear that this work had a separate genesis and should be regarded as orthogonal to the earlier work. In fact I concur with the cited authors in finding considerable overlap among these works, though I will point out some divergences and shifts of emphasis in the course of this paper. In particular, BSD shifts from using the term "practices" to the more non-committal "practices-or-abilities", which makes room for a more psychologistic or cognitivist approach.

3. Clark (2015) considers this connection to be "tenuous". 
Much of MIE is taken up with showing how one can proceed in a top-down manner to account for phenomena that are more conventionally studied under the banner of linguistic semantics such as: the "meaning" or inferential roles of terms and predicates; conditionals and negation; anaphora; modality; and de re/de dicto distinctions. In this paper we are primarily concerned with one particular aspect of this programme, logical expressivism: this is essentially the thesis that

i. linguistic competence involving the use of concepts minimally involves an ability to make inferences: for instance, to correctly use the term red one must endorse the inference that "red" is a colour, if something is red it is not green, and so on;

ii. the ability to make and endorse inferences is not the same as the ability to articulate them, as it need not involve the use of logical vocabulary such as if... then;

iii. logical operators serve to make explicit patterns of inference which are already available in a hypothetical "base" language that lacks this vocabulary;

iv. the introduction of these operators is semantically transparent and inferentially conservative, in that their use does not enable any inferences which were not previously available.

The expressivist project is presented in BSD in terms of the notions of elaboration and explication. The idea is that a set of basic abilities can be marshalled into a process which implements a higherlevel ability (elaboration), and that one can then define a vocabulary that specifies or codifies this set of practices (explication). In the particular case of logical expressivism, the argument is that this elaboration/explication (LX) relation enables speakers to say whether a particular inference is good or bad, rather than simply treating it as such. The act of "saying" is realised in this case through the conditional locution.

This paper takes a close look at some empirical aspects of logical expressivism and in particular at the expressivist account of formal validity: inferences involving logical vocabulary are said to be formally good if they are both materially good, and cannot be made materially bad by uniform substitution of nonlogical for nonlogical vocabulary in the premises and the conclusions (Brandom, 2000, p. 55). We adduce a range of empirical evidence that poses serious challenges for this approach, and argue that it underestimates the pervasive effects of context on the interpretation of connectives. As a preliminary, we will need to take a closer look at exactly what is meant by material inference.

Note to begin with that as far as we are aware, neither Brandom nor any of his commentators have offered a fleshed-out demonstration of how such a substitutional methodology would work. There have been a number of formal treatments with varying degrees of faithfulness to Brandom's account: Lance and Kremer (Lance and Kremer, 1994, 1996; Lance, 2001) employ modal and relevance logics, Piwek $(2011 ; 2014)$ gives a proof-theoretical account, Kibble $(2004 ; 2006 ; 2007)$ uses Amsterdam-style dynamic semantics, and Brandom himself, with Alp Aker, (Brandom, 2008) defines an "incompatibility semantics" (IS) as an algebra over certain stipulated basic operations. However, none of these proceeds by starting with natural language and using substitutional techniques to (a) demarcate syntactic categories and/or (b) explicate the inferential roles of items which are identified as logical vocabulary. Rather, each presentation only informally associates formulas from the formal system with selected (typically, constructed) natural language expressions. In fact, Lance and Kremer (1994, p. 373) deliberately eschew expressivism understood as an encoding of "social criteria of inferential appropriateness" on the grounds that it could entail cultural 
relativism ${ }^{4}$, while Kukla and Lance (2009) do not assume any systematic correspondence between "surface grammar" constructions and pragmatic actions, and Kibble (2006) suggests that Brandom's mechanism of deontic scoreboards can be detached from the inferentialist project. We argue in what follows that such a thorough-going expressivist programme would in fact face significant difficulties, arising from the pervasive context-dependence and idiomaticity of natural language expressions even including logical terms, and the difficulty of identifying logical vocabulary itself. We will reach a tentative conclusion that fomal validity of inference is not a property of natural language, which rather consists of clusters of micro-practices or Wittgensteinian language games.

A major theme of this paper is Brandom's rational reconstruction of the genesis of conditional constructions in natural language. The claim is that any discursive practice must include a "core" of assertional practices, since assertions are the only speech act that can be performed without mastery of any other types of locution, and that those engaging in such an autonomous discursive practice or ADP will be able to recognise and endorse inferential links between assertions, which are codified or made explicit by the introduction of logical vocabulary (Brandom, 2000, pp. 45-78). In other words, the ability to make and endorse "material" inferences is taken to be both necessary and sufficient for acquiring the ability to correctly deploy logical vocabulary, in particular the conditional locution. We will argue that it is not clear whether speaker/hearers would be reliably capable of distinguishing between elaborative (providing further information) and inferential links, and that the introduction of conditional locutions is not inferentially conservative as Brandom argues, since they provide a vocabulary for postulating hypothetical/irrealis states of affairs which are not available in a basic assertional practice ${ }^{5}$. We will instead propose an intermediate stage involving directive acts of the type which have been called pseudo-imperatives in the literature (Fox, 2015), such as Write a song about Pale Fire and he's yours! These acts have the grammatical form of an imperative conjoined with an assertion but are typically interpreted as having the force of conditional statements, and it will be argued that Kukla and Lance's account of directives helps us assign a conditional semantics to these constructions in a rather natural way which still slots into Brandom's scheme of elaboration and explication. The first strand in this argument is supported with reference to a corpus study of elaborative and argumentative discourse relations (Scholman and Demberg, 2017), and we also draw on a number of examples from the MultiNLI ${ }^{6}$ corpus (Williams et al., 2017). We sketch a conjectural genesis of the conditional locution in goal-directed cooperative dialogue, which turns out to fit neatly within Brandom's close coupling of propositional and practical commitments.

It should be noted that a purely assertional ADP seems lacking for the game of "giving and asking for reasons", since it would include no locutions for asking - the only way to challenge a commitment is by asserting an incompatible proposition. Wanderer (2009) argues for the inclusion of a "challenge" locution and this is conceded by Brandom (2009b) - note that this development is in fact anticipated by Kibble $(2006 ; 2007)^{7}$. (We should also note Belnap's (1990) trenchant arguments that any analysis of language restricted to the declarative form is fundamentally impov-

4. (Piwek, 2011, p. 48) argues persuasively that the danger of cultural relativism does not arise if we conceive of logical theory as consisting of "materially non-substantive inferences".

5. Note that Weiss (2009) questions whether the augmentation of a base language with logical operators can be truly said to be "conservative". Piwek (2011) shows that this can only hold if we assume unlimited time and memory.

6. Multi-Genre Natural Language Inference

7. (Brandom, 1994, p.193) notes the potential utilty of distinguishing queries and challenges as distinct speech acts, though these remarks remain undeveloped and there is little discussion of their impact on the deontic status of interlocutors. 
erished, while the semantics of questions is a long-established field of study (Wiśniewski, 2015), (Ginzburg, 2017).)

Section 2 gives a brief overview of Brandom's notion of discursive practice in terms of deontic scorekeeping. Subsequent sections will proceed from the particular to the general:

- Section 3 presents empirical data which appears to pose problems for Brandom's treatment of formal validity in terms of material goodness of inference;

- Section 4 reviews some criticisms of Brandom's notion of the introduction of conditionals into a base language via algorithmic elaboration, and proposes an alternative dialogical account of the genesis of conditionals via the introduction of directives;

- Section 5 sets out some technical details of this proposal, in terms of information state-based dialogue modelling in the style of Traum et al. (1999);

- Section 6 takes a more foundational stance and attempts to situate Brandom's discursive practices within the context of practice theory as exemplified by Bourdieu (1977), Rouse (2002) and Narasimhan et al. (2017).

- Finally, we draw up some tentative conclusions and indicate directions for future work.

There are a number of tutorial accounts of Brandom's approach to semantics and pragmatics, such as Wanderer (2008); Turbanti (2017); Loeffler (2018) which are all to be recommended. This paper differs in emphasis from those works in confronting Brandom's claims with detailed linguistic analysis, and in seeking to clarify his notion of discursive practice in comparison with key work in the established field of practice theory.

\section{Discursive Practice and Material Inference}

\subsection{Brandom's inferentialist programme in a nutshell}

1. Brandom's inferentialism is a variant of speech act theory, which in contrast to the tradition represented by Grice (1957) and Searle (1969) treats utterances as actions which have effects in social space rather than primarily as expressions of mental states seeking to modify the mental states of interlocutors. For Brandom, the effects of utterances are manifested in the deontic status of discourse participants, that is in the array of propositions which they are committed to justifying if challenged and in the entitlements they may claim to these commitments.

2. The primary units of "meaning" in language are propositions, as the smallest elements for which one can take responsibility, and propositional inferences which are governed by social practice. Uttering a proposition is akin to moving a counter in a game, and is subject to socially-governed rules or conventions which determine the preconditions and effects of making a move.

3. Entailment is defined in terms of a primitive notion of incompatibility: P incompatibilityentails $\mathrm{Q}$ if everything incompatible with $\mathrm{P}$ is incompatible with $\mathrm{Q}$. This notion underlies patterns of inference which are manifest in dialogue moves. 
4. The inferential potential of subsentential units can be determined though a form of top-down compositionality, by substitution of terms within a proposition and comparing the difference this makes to the inferences which are licensed.

5. Substitutions may be symmetric or asymmetric in their effects. For example if the substitution inference from (a) Benjamin Franklin invented bifocals to (b) The first Postmaster General of the United States invented bifocals is a good one, then so is the converse inference from (b) to (a) (symmetric), while the material goodness of the substitution inference from (a) Thera walks to (b) Thera moves does not ensure the material goodness of the converse inference (asymmetric). The first example involves terms and the second predicates.

6. As noted above, MIE proposes that the substitution-inferential method can be extended to handle many phenomena which make up the bread-and-butter of formal semantics, such as anaphora and de re/de dicto reference. In particular, it is argued that inferences involving logical vocabulary have the characteristic that their validity is unaffected by substitution of non-logical for non-logical vocabulary. So, If Boris is a liar and a scoundrel, then Boris is a liar will be a valid inference whatever expressions we choose to insert in place of Boris, liar and scoundrel.

7. Utterances are considered under two aspects: as things that we do and as ways of saying things. For example: Fido is a dog. He has warm blood manifests the inference that dogs are generally warm-blooded, but does not explicitly say that this is how things are (If $X$ is a dog, $X$ is warm-blooded).

8. Any discursive practice must minimally include assertion and (propositional) inference; any speaker/hearer who has mastered these practices has all the discursive abilities which are required to deploy logical vocabulary including conditionals and modal operators. The introduction of such vocabulary enables us to articulate and talk about inferences, while maintaining conservativity in that no new inferences will be licensed which are not available to practitioners using a logic-free vocabulary. So If something is a dog, it is warm-blooded; Fido is a dog, so Fido is warm-blooded manifests the same inference as the example above, but explicitly states it as an instance of a general rule rather than implicitly applying a material inference.

9. A key point is that the notion of "material inference" which Brandom adopts from Sellars holds that the inference follows immediately by virtue of the content of the expressions, and that "material properties of inference [are treated] as prior in the order of explanation to formal logical properties of inference" (MIE: 135). The propriety of inference is a matter of normative assessment: a good (material) inference is one which members of a language community ought to endorse, and which they can reasonably expect others to endorse. This may cover inferences based on scientific knowledge, on tautologies, or general knowledge, as in Eastbourne is west of Hastings, so Hastings is east of Eastbourne.;

Clearly much of this is of a programmatic nature: a recent tutorial account considers Brandom's substitutional mechanism to be "unsatisfactory both for the logician, because it is silent about quantification, and for the linguist, because it hardly accounts for basic predication" (Turbanti, 2017, p. 81). Unlike the currently dominant formal and distributional approaches to NL semantics it is hard 
to see how Brandom's claims could be empirically evaluated in a robust manner - though as indicated above, one can extract falsifiable hypotheses from his work and one such hypothesis will be investigated below. Nevertheless, we will argue that his framework provides a fruitful environment for investigating the close coupling of language and action, since both are treated within a unitary framework of commitment.

\subsection{Deontic scoreboards and material inference}

To repeat, Brandom's approach is concerned with "deontic" attitudes of hearers, and of speakers as self-monitors, rather than intentional attitudes of speakers as in classic Speech Act theory. In place of beliefs and desires, Brandom discusses "doxastic" and practical commitments, corresponding to beliefs and intentions respectively, which interacting agents may acknowledge or ascribe to one another ${ }^{8}$. The normative dimensions of language use according to Brandom comprise responsibility if I make a claim, I am obliged to back it up with appropriate evidence, argumentation and so on and authority - by making a claim to which I am assumed to be entitled, I license others to make the same claim. The essential idea is that making an assertion is taking on a commitment to defend that assertion if challenged. There are obvious shared concerns with the notions of commitment developed by Hamblin (1970) and Walton and Krabbe (1995), and subsequently taken up in multi-agent systems (Singh, 2000) and computational linguistics (Matheson et al., 2000). Brandom's elaborations include the notion of entitlement to commitments by virtue of evidence, argumentation etc; the interpersonal inheritance of commitments and entitlements, and the treatment of consequential commitments and incompatibility. The mechanism for keeping track of agents' commitments and entitlements consists of deontic scoreboards maintained by each interlocutor, which record the set of commitments and entitlements which agents claim, acknowledge and attribute to one another (claims and acknowledgements are forms of self-attribution). Scoreboards are perspectival and may include both explicitly claimed commitments and consequential commitments derived by (material) inference. In the pure model, each agent maintains their own scoreboard and none has any privileged authority: in practice, agents will often defer to others on grounds of specialist knowledge, experience, status or indeed, power. Agents may be in a position of claiming incompatible commitments but may not be assessed as entitled to more than one of them (if any).

In Brandom's model, entitlement to a commitment mostly arises in one of two ways: by inference from a commitment to which one is already entitled, or by deferral to the testimony of an interlocutor who is entitled to the commitment. Stated thus simply, there is an obvious threat of infinite regress on both scores, since it appears we may not in general acquire any entitlements unless there are already commitments that we or our interlocutors are entitled to. Brandom finesses this danger by proposing a "default and challenge" model: entitlement to a commitment is often attributed by default, though remaining potentially liable to be challenged by the assertion of an incompatible commitment. To keep things manageable, the more formal treatment in section 4 will mostly deal only with attributions of commitments by one agent to another.

Material inference is somewhat cursorily introduced as follows:

The kind of inference whose correctnesses determine the conceptual content of its premises and conclusions may be called, following Sellars, material inferences.

(Brandom, 2000, p.52)

8. Strictly speaking, Brandom's analogue of belief is acknowledgement of a doxastic commitment. 
Examples given are: "Pittsburgh is to the west of Princeton, so Princeton is to the east of Pittsburgh" and "Lightning is seen now, so thunder will be heard soon". Many people encountering Brandom's work find the notion of material inference puzzling and suspicious, particularly in the way it seems to provide free inference tickets for deriving "ought" from "is". In fact, it seems that the disposition to make or endorse such inferences is taken to be part of the practical ability involved in the mastery of a particular vocabulary or field of activity, as is the ability to recognise incompatibilities among commitments. The key point is that these inferences are seen as normatively governed, as noted earlier, in that any rational member of the language community ought to endorse them and can reasonably expect others to endorse them. This may encompass inferences based on, for example, accepted scientific knowledge, rules of mathematics, or general knowledge:

\section{Example 1}

(a) The kettle is heated to $100^{\circ} \mathrm{C}$ so it will boil.

(b) Brockley is in London and London is in England, so Brockley is in England.

(c) Two angles of a triangle are to $40^{\circ}$ and $60^{\circ}$, so the third is $80^{\circ}$.

It will be noted that some of these inferences are defeasible: the boiling point of water depends on the atmospheric pressure, while the geographical extent of cities can be changed by administrative fiat. Material inferences are seen as pre-logical and do not involve tacit formal reasoning involving a hidden premise or enthymeme such as "If lightning is seen, thunder is heard shortly after". Nor does this normative approach make use of Carnapian "meaning postulates" (Carnap, 1952), a standard device for capturing "lexical" entailments in formal semantics such as $\forall x(B(x) \rightarrow \neg M(x))$, where $B$ denotes the set of bachelors and $M$ the set of married people. Rather, such conditional statements are seen as formally making explicit the content of the inference, with the result that inferences themselves can become topics of scrutiny and discussion. Brandom's "origin myth" for formal reasoning postulates an introduction of logical vocabulary such as conditionals into a language in which inferences may be performed but not talked about, so that we are subsequently able to say what we can only $d o$ using the relatively impoverished language. This is subject to a principle of conservativeness, in that the new vocabulary must not license any new inferences involving the old vocabulary (op cit, p. 68). This theme is systematically developed in Brandom (2008) and is considered further in the next section.

\subsection{Action and practical commitments}

Brandom's account of action and intention is initially quite similar to the doxastic story in its overall structure: the role of intentions is taken by practical commitments which can stand in inferential relations to doxastic or to other practical commitments, and to which one may be entitled or not entitled. It is notable that practical commitments can be inferred from doxastic commitments and vice versa, as in the examples below:

\section{Example 2}

i. Only opening my umbrella will keep me dry, so I shall open my umbrella. 


\section{ii. I am a bank employee going to work, so I shall wear a tie.}

(Brandom, 2000, p. 84)

iii. I have a fever, so I shall see the doctor.

Piwek (2011)

Brandom argues that these inferences are not enthymematic, relying on suppressed premises "I wish to stay dry" or "Bank employees should wear ties", but that (i.) and (ii.) above are further examples of "material inference": the consequent follows from the antecedent by virtue of its content, and the putative "suppressed premises" are ways of making explicit the implicit norms or preferences that make the inferences go through.

Practical commitments are taken to stand in inferential relations with both doxastic and other practical commitments, and an action is taken to be rational if it fulfils a practical commitment for which the agent can give a reason. For example: "Why are you wearing a tie?" "I'm on the way to work". Putting things a little more technically: to demonstrate entitlement is to offer a chain of reasoning which terminates in a practical commitment which is compatible with one's other acknowledged commitments, and actions result from "reliable dispositions to respond differentially to the acknowledgement of certain sorts of commitments" (Brandom, 2000, p. 83). Scorekeepers are licensed to infer agents' beliefs from their intentional actions [Ibid.].

\subsection{Compositionality}

Further, material inference has a role to play in analysing the semantic content of subsentential expressions:

Two subsentential expressions of the same grammatical category share a semantic content just in case substituting one for the other preserves the pragmatic potential of the sentences in which they occur... a pair of sentences may be said to have the same pragmatic potential if across the whole variety of possible contexts their utterance would be speech acts with the same pragmatic significance...

(Brandom, 1994, pp. 128-9)

So for example, one might say that two terms have the same denotation ("representation") if replacing one with the other makes no difference to the appropriate circumstances in which a speech act may be uttered and its pragmatic consequences, in terms of the speaker's deontic score. Much of the second half of MIE consists of elaborations of this substitutional technique to handle the traditional subject matter of formal semantics such as reference, anaphora, deixis, quantification and propositional attitudes.

Kremer (2009) offers a detailed examination of the decompositional strategy of analysing the content of subsentential expressions, and identifying different subcategories such as terms and predicates according to the contribution they make to the inferential potential of propositional utterances. For example: the fact that one can infer Thora is a mammal from Thora is a dog, but not vice versa, indicates that mammal and $d o g$ are predicates which licence asymmetric substitution inferences, rather than terms which may license symmetric inferences (Brandom, 1994, pp. 133ff). Kremer argues that Brandom's account is plagued with circularity, since it claims to define syntactic categories in terms of substitution inferences but turns out (on Kremer's account) to assume a prior grasp of these very categories. One could add that the substitutional techniques are presented in 
rather general terms, using simple examples, and would constitute a formidable machine learning problem if applied to corpora of actual discourse. For one thing, it is unlikely that any corpus would provide instances of "all possible contexts" for any given sentence-pair (see above), and this in any case assumes agents with unlimited cognitive resources. As noted, we argue below that Brandom's programme severely underplays the pervasive nature of context-dependence in natural language understanding, such that it is problematic to posit invariant semantic content/inferential potential for particular words or phrases even including "logical" expressions.

\subsection{Two aspects of logical expressivisim}

The expressivist project can be approached in various ways. One is to start by modelling forms of inferential practice which underly or are implicit in the use of ordinary vocabulary, and investigate how these practices can be described or articulated with the aid of logical vocabulary. This is the approach taken by Piwek (2011), who postulates various inferential practices employed in cooperative information-seeking dialogues in a medical domain, such as deriving $s d$ ("See a doctor") from $h t$ ("Has a temperature"). These inferential practices are modelled as natural deduction inference rules - for example, a rule labelled $h t \_t o \_s d$ "stands for the practical ability to derive $s d$ when $h t$ already follows" (op cit:266). These inference rules are supplemented with introduction rules which will, for example, license the assertion of $h t \rightarrow s d$ just in the case that the rule $h t \_t o \_s d$ applies:

$$
\begin{gathered}
\frac{h t \in \Gamma}{\{h t\} \vdash h t} \\
\underline{\emptyset \frac{1 h t\} \vdash s d}{\vdash h t \rightarrow s d}}
\end{gathered}
$$

This is an elegant proposal which ensures that logical connectives will only be employed when licensed by inferences which are implicit in the knowledge base, and so the requirement of conservativity will be satisfied.

An alternative way to approach the issue is to start from everyday sayings and conversations and investigate whether a class of vocabulary items can be identified which behave in the same way as logical connectives in a system like Piwek's: that is, they invariably articulate or denote patterns of inference which are implicit in the knowledge base, by virtue of the nonlogical content of their arguments. This is the path suggested by Brandom in his distinction between material and formal goodness of inference:

.... an inference can be treated as good in virtue of its form, with respect to [some privileged subset of] vocabulary, just in case

It is a materially good inference, and

It cannot be turned into a materially bad one by substituting nonprivileged for nonprivileged vocabulary in its premises and conclusions.

(Brandom, 2000, p. 55)

It is not obvious a priori that any such class must exist. Piwek acknowledges that

In principle, there is nothing that excludes the existence of a language community which can make practical inferences involving materially substantive propositions (such as $h t$ and $s d$ ), but which has not mastered any logical vocabulary. (Ibid.) 
One could also argue that nothing in principle excludes the existence of a community that has no universally applicable logical vocabulary, but which either uses different vocabularies or interprets logical expressions in different ways in the context of particular domains. And indeed it would be quite in the spirit of Brandom's Wittgensteinian heritage if even logical terminology turned out not to have a common core of meaning or inferential potential across all contexts of use, but rather manifested "family resemblances" (Wittgenstein, 2009, § 65-71). This will be the topic of section 3 in this paper.

\subsection{Summary}

In summary, participation in a discursive practice in Brandom's terms minimally involves:

- ability to deploy a vocabulary in ways which are acceptable to other members of a speech community;

- ability to make and endorse a variety of material inferences;

- ability to keep score of commitments undertaken by interlocutors and oneself, to recognise incompatible commitments, and to ascribe both entitlements and consequential commitments to participants in a discourse;

- ability to challenge other practitioners who are assessed as not entitled to particular commitments.

Note that none of these bullet-points specifically mentions meanings, beliefs or intentions, but it is claimed that a practice involving these abilities can count as a linguistic or discursive practice. Note also that the practice involves an abstract notion of a "scoreboard" and is essentially normative, concerned not so much with observed practices as with what agents ought to be able to do to count as engaging in dialogue.

\section{Context-dependence of interpretation}

To recapitulate: according to the expressivist account of formal validity, inferences involving logical vocabulary are said to be formally good if they are both materially good, and cannot be made materially bad by uniform substitution of nonlogical for nonlogical vocabulary in the premises and the conclusions (Brandom, 2000, p. 55), as in the following example:

\section{Example 3}

i. All ravens are black. Matthew is a raven, therefore Matthew is black.

ii. All babies are cute. Oscar is a baby, therefore Oscar is cute.

The implication is that logical connectives have an invariant meaning which is preserved across linguistic contexts. This is an empirical claim, and this section aims to marshall evidence which puts the claim in doubt.

This section approaches the issue from two directions. On the one hand, we investigate whether it is possible to identify formally valid inference patterns in natural language according to Brandom's substitution method; it turns out that with some ingenuity, counter-examples can be constructed that invalidate a variety of inferences which appear materially good on first inspection. On 
the other, we discuss whether the types of inferences licensed by proof-theoretic schemes such as Natural Deduction are actually manifest in NL, using connectives which are commonly associated with Boolean operations. Both strategies are concerned with the question of whether there really is a route from natural language discourse to at least some of the commonly accepted inference rules for formal logics, without the digression of constructing and stipulating interpretations for formal or controlled languages. The following sections look in detail at a number of candidates for consideration as "logical vocabulary", namely and, or, if...then, may/must, not and all. Few of these examples are particularly novel, but taken together they pose a substantial challenge to the claims of logical expresssivism.

\subsection{Examples of "logical" vocabulary}

\subsubsection{AND}

Well-known issues with and involve non-intersective adjectives: while (b-f) in Example 4 below can all be inferred from (a), the same does not hold for Example 5 with the non-logical term "brilliant" substituted for "Irish", which implies that the inferences in (4) are not all formally valid.

\section{Example 4}

(a) Joyce is an Irish author and a father.

(b) Joyce is Irish and Joyce is an author.

(c) Joyce is Irish.

(d) Joyce is an author.

(e) Joyce is a father.

(f) Joyce is an Irish father.

\section{Example 5}

(a) Joyce is a brilliant writer and a father.

(b) Joyce is brilliant and Joyce is a writer.

(c) Joyce is brilliant.

(d) Joyce is a writer.

(e) Joyce is a father.

(f) *Joyce is a brilliant father.

Kamp (2004) assumes the following classification of adjectives:

predicative: If every $\mathrm{N}_{1}$ is an $\mathrm{N}_{2}$, then every $\mathrm{AN}_{1}$ is an $\mathrm{AN}_{2}$. Examples: fourlegged, superconductive. 
privative: No $\mathrm{AN}$ is an $\mathrm{N}$ : fake, false, former(? $)^{9}$

affirmative: Every $\mathrm{AN}$ is an $\mathrm{N}$ : big, pink, clever

extensional: Every AN is A: red, female ... "Clearly, all predicative adjectives are extensional. Non-extensional adjectives are, for example, affectionate and skillful" (op cit: 543).

Clearly, goodness of material inference under substitution of nonlogical terms depends on selecting adjectives from the appropriate class, rather than freely substituting nonlogical vocabulary. So the inferences in (4) go through because Irish is treated as extensional, while (5) fails because brilliant is not. We should note that Kamp carefully qualifies these distinctions with the phrase "in an interpretation": adjectives need not manifest the same behaviour in all contexts. In fact it is debatable whether any adjectives are truly extensional: e.g., colour terms are highly context-dependent - compare white paper, white wine, white coffee, white rhino, while Posner (2004, p. 640) reports that the same colour can be called rot "red" or braun "brown" in German, depending whether it occurs on a cotton coat or a plastic wall respectively.

INFERENCES UNDER CONJUNCTION

Conjunction in ordinary English typically licenses various inferences which are not reducible to the accepted truth-functional definition (examples 6 and 7 adapted from Posner (2004)).

\section{SUCCESSIVITY}

There is a strong implication that conjoined sentences narrate events in the order of occurrence: so (6c) implies (6e) while (6d) implies (6f). Neither (6e) nor (6f) can safely be inferred from commitment to (6a) and (6b) separately.

\section{Example 6}

(a) Annie married Peter.

(b) Annie had a baby.

(c) Annie married Peter and had a baby.

(d) Annie had a baby and married Peter.

(e) Annie had a baby after she married Peter.

(f) Annie married Peter after she had a baby.

\section{CONNEXITY}

There is an implication that conjoined sentences relate to the same situation. So (7d) is felt to imply (7f) while (7e) implies (7g). It would be uncooperative to utter either (7d) or (7e) if one is committed to all of $(7 \mathrm{a}-\mathrm{c})$.

9. Though arguably, if a past US President becomes president of a university, they are both a president and a former president. 


\section{Example 7}

(a) The door is open.

(b) The window is open.

(c) There is a draught.

(d) The door is open and there is a draught.

(e) The window is open and there is a draught.

(f) There is a draught from the open door.

(g) There is a draught from the open window.

Note that these implications are cancellable: one may say for example, "Annie married Peter and had a baby, but not in that order", or "The door is open and there is a draught, but it's not from the door".

WHEN and BEHAVES LIKE A CONDITIONAL

Examples below are taken from the SNLI and MultiNLI corpora (Bowman et al., 2015; Williams et al., 2017). These corpora were constructed to support the development of techniques for recognising entailments in NL text, providing a copious variety of inferentially linked sentence-pairs based on corpus data and incorporating native speaker judgments. Both corpora include instances of NL text that were originally constructed for other purposes (referred to below as premises), and each example was given to participants who were asked to produce new sentences which were entailed or contradicted by, or merely compatible with the original example (referred to as conclusions). Instructions were given in non-technical language: participants were asked to say whether their sentence was definitely correct, might be correct or was definitely incorrect in the specified context. The data thus allows insight into informal everyday inference with minimal contamination from expert ideas about entailment, deduction or what have you. In particular, this somewhat ecumenical treatment shows that naive informants are prepared to treat non-declarative utterances as premises in an inference, pace Belnap $(1990)^{10}$. Subjects seem to have interpreted the instructions differently; some have effectively given a paraphase of the original rather than an entailment. The SNLI corpus consisted entirely of descriptive captions for photos on the Flickr website, while MultiNLI uses written and transcribed material from a variety of genres. The material is provided in plain text, JSON and parsed variants.

The examples discussed in this section were obtained by writing a script to extract sentence pairs with the following characteristics:

- The pair is flagged as "entailment"

- The premises do not contain the word "if"

10. Belnap calls the assumption that all utterances share a cluster of properties, including the potential to act as premises for inference, the "Declarative Fallacy". A reviewer points out that premises or conclusions can be questions in erotetic logic (Wiśniewski, 2013) 
- The premises may consist of two or more clauses (as a rough and ready test, we looked for the word and)

- The conclusion begins with "If".

A selection of the sentence pairs were manually extracted for discussion in this paper ${ }^{11}$. It was hoped that this would furnish instances of the introduction of logical vocabulary to form a conditional where the premise contains inferentially linked conjuncts, and this hope was satisfied to an extent. However there is a key difference in that while Brandom envisages conditionals as arising within a purely assertional practice, many of our examples consist of an imperative followed by an assertion, which is interpreted as entailing a conditional: Do $X$ and $Y \rightsquigarrow I f(D o n e X)$ then $Y^{12}$. Importantly, these constructions are not necessarily interpreted as entailing either of the conjuncts independently, as might be expected via $\wedge$-Elimination: e.g., the speaker of Example 9 is probably not advising the hearer to sneeze or develop a fever.

\section{Example 8}

(a) Get individuals to invest their time and the funding will follow.

(b) If individuals will invest their time, funding will come along, too.

\section{Example 9}

(a) Sneeze in the middle of the night and your Edokko neighbor will demand the next morning that you take better care of yourself; stay home with a fever and she will be over by noon with a bowl of soup.

(b) If you develop a fever which results in you staying home, your Edokko neighbor will arrive by midday with soup.

\section{Example 10}

(a) Truce. You stop this train, everyone lives.

(b) If you stop this train everyone will live.

\section{LITERARY EXAMPLES AND PROVERBS}

\section{Example 11}

(a) Use every man after his desert, and who should 'scape whipping? (Hamlet)

(b) If you treated everyone as they deserved...

\section{Example 12}

(a) Feed a cold and starve a fever.

11. A fuller list can be found in the Appendix.

12. These constructions are known as pseudo-imperatives in the literature Fox (2015). 
(b) If you feed someone who has a cold, they will develop a fever ... ${ }^{13}$

The reader may consider that I am using the term "entailment" rather loosely in talking about the entailments of an imperative. In section $4 \mathrm{I}$ will try to tighten up this talk, and will explore a conjecture that the conditional form as manifested in the (b) sentences above is ultimately derivative on complex commands like those in the (a) sentences. I will argue that this approach leads to a more satisfying account of the introduction of conditionals into a base language than Brandom's so-called algorithmic elaboration.

\subsubsection{OR}

\section{WHEN or BEHAVES (SOMEWHAT) LIKE CONJUNCTION}

Jennings (2004) discusses this connective at some length and contends that it does not typically behave like truth-functional disjunction, even in the context of selected examples from logic books. For instance, he argues that or in example (13), attributed to Patrick Suppes, is not a case of exclusive disjunction as Suppes maintains:

Example 13 Father to child: "You may go to the movies or you may go to the circus this Saturday but not both”. (op cit, p. 665)

This is not a disjunction because the child may legitimately infer that they have permission to go to the movies, and that they have permission to go to the circus. However, the truth-functional definition of XOR does not licence $P X O R Q \vdash Q$, or $P X O R Q \vdash P$. The meaning of (13) can be more accurately captured as: MAY(movies AND NOT circus) AND MAY(circus AND NOT movies), where there is no disjunction in sight. Jennings (Jennings, 2004, p. 671) claims that "All the connective vocabulary of any natural language has descended from lexical vocabulary" e.g. or from OE odher "other", but from OE butan "outside", while "much of the vocabulary retains residual nonlogical ... uses (since, then, therefore, ... )". While Brandom's story of logical vocabulary being introduced into a language lacking such terms is not to be taken too literally, it may well be the case that a class of lexical terms have acquired logical uses in the course of a language's history but a residue persists of non-logical uses.

\subsubsection{IF/THEN}

We would like to think that a simple conditional "P if Q" will always imply "If Q then P", but it's not so simple as Lakoff showed in his paper on "Natural Logic" (Lakoff, 1970):

\section{Example 14}

(a) I think Sam will smoke pot ${ }^{14}$, if he can get it cheap.

(b) If he can get it cheap, then I think Sam will smoke pot.

13. "As Robert Graves has pointed out, this archaic source of error treats the two apparent imperatives as separate injunctions, whereas what we have is in fact a conditional sentence: if you feed somebody with a cold, he [sic] will develop a fever and them you will have to starve him" (Amis, 1999). Admittedly this proverb gives doubtful advice on either this or the more literal reading.

14. pot: cannabis (archaic). 


\section{Example 15}

(a) I realize that Sam will smoke pot, if he can get it cheap.

(b) *If he can get it cheap, then I realize that Sam will smoke pot.

The reader may object that this is not a simple conditional, but the conditional occurs as the complement of an attitudinal verb. Nevertheless the fact remains that what is a good inference in one case is turned into a bad one simply by substituting nonlogical vocabulary items. (A reviewer argues that examples (14) and (15) differ in that I think functions parenthetically whereas I realize actually embeds a conditional under the attitudinal verb. This relies on a degree of syntactic analysis which is not supposed to be available under Brandom's substitutional methodology. The parenthetical function can be made unambiguous through punctuation: If he can get it cheap, then, I think, Sam will smoke pot.)

\subsubsection{Modality AND NEGATION}

We would expect to treat inferences of the form If $P$ then Must- $Q$ implies If $P$ then $\neg M a y \neg Q$ as formally valid. However:

\section{Example 16}

(a) Shoes must be worn in the library.

(b) [if you are in the library, you must wear shoes]

(c) You may not use the library if you are not wearing shoes.

\section{Example 17}

(a) Dogs must be carried on the escalator.

(b) [if you ride the escalator, you must carry your dog]

(c) *You may not use the escalator if you are not carrying dogs.

Clearly, the distinction relies on cultural knowledge about expected behaviour in different contexts. The natural understanding of 16(a) is consistent with the above equivalence, whereas 17(a) needs to be unpacked as If you ride the escalator with your dog, you must carry it. Again, the point here is that uniform substitution of non-logical vocabulary can fail to preserve logical inference ${ }^{15}$.

\subsubsection{QUANTIFICATION AND COMPOUND NOUNS}

\section{Example 18}

(a) All horses are animals. So, all horse tails are animal tails. (De Morgan, quoted by van Benthem (2007)).

(b) *All horses are animals. So, all horse boxes are animal boxes.

15. A reviewer states that the natural readings for these sentences rely on distinct intonational patterns; however, these admonitions are more likely to be found on printed signs. 
(c) All dogs are animals. So, all dog coats are animal coats.

(d) *All minks are animals. So, all mink coats are animal coats.

According to van Benthem, example (a) was routinely presented to Dutch logic students in the 1960s as part of their initiation into the predicate calculus. The inference (b) fails, I contend, because a horse box is not the same kind of thing as an animal box: the former is not a box at all, but a vantype vehicle for transporting horses, while the latter might be understood (if at all) as a box of treats for pet animals such as toys, accessories and hygiene products, or perhaps a small container for carrying pets. Likewise (d) fails if we read "animals coats" in a natural way as "coats for animals" as in the unobjectionable (c): the natural reading of "mink coat" is of course a coat made from the pelts of minks.

Bauer and Tarasova (2013) discusses nominal compounds, using the following classification from Levi (1978):

N1 CAUSE N2 sex scandal, withdrawal symptom

N2 CAUSE N1 tear gas, shock news

N1 HAVE N2 lemon peel, school gate

N2 HAVE N1 camera phone, picture book

N1 MAKE N2 court order,

N2 MAKE N1 computer industry, silk worm

N2 USE N1 steam iron, wind farm

$\mathrm{N} 2 \mathrm{BE} \mathrm{N} 1$ island state, soldier ant

N2 IN N1 field mouse, letter bomb

N2 FOR N1 arms budget, steak knife, machine oil

N2 FROM N1 business profit, olive oil

N2 ABOUT N1 tax law, love letter, business news

Bauer's discussion exclusively concerns endocentric compounds: that is, every $\mathrm{N}_{1} \mathrm{~N}_{2}$ is an $\mathrm{N}_{2}$. So while horse tails, animal tails, mink coats are endocentric, horse boxes are not, which may account for the failure of (b). And while animal coat, dog coat are instances of N2 FOR N1, mink coat is a case of N2 FROM N1, and thus (d) is blocked. As with the different types of adjectives mentioned in section 3.1.1, material goodness of inference can only be preserved under inference if substituted items are limited to an appropriate class; a difficulty is that these associations are often idiomatic and idiosyncratic and can't be reliably predicted from the content of the two nouns on their own.

\subsection{Summary}

To summarise: in this section we have considered various examples which appear to challenge the notion that logical connectives can be extracted from natural language practice by identifying invariant uses under substitution of the accompanying non-logical vocabulary, owing to the pervasive influence of linguistic and non-linguistic context on the behaviour of lexical items including even "logical" terms. The evidence above suggests that when we look closely at the behaviour of socalled 'logical' connectives, we do not find uses which are invariant under substitution but rather, clusters of evolving micro-practices or language games associated with the use of particular items and constructions. In the next section I investigate one of these practices in some detail, proposing a non-standard account of commands and commitments which may offer a plausible model for the conditional sense of complex directives. 


\section{Towards a dialogical account of conditionals}

\subsection{Algorithmic Elaboration}

One specific type of elaboration focussed on in Brandom (2008) is the introduction of conditionals into a purely assertional autonomous discourse practice. Brandom claims (op cit, p45) that an ability to respond appropriately to conditional statements of the form "If $P$ then $Q$ " can be acquired by an agent that has mastered core elements of an ADP such as

the abilitites to make assertions/acknowledge assertional commitments, to acknowledge inferential commitments relating certain statements $\mathrm{P}$ and $\mathrm{Q}$ of the practice, and to reliably respond differentially to assertions or changes in one's deontic attitude by altering the score.

(Loeffler, 2018, p. 153)

Such development of new discursive practices involving the exercise of "exercising the right basic abilities in the right order and under the right circumstances" (Brandom, 2008, p. 26) is dubbed algorithmic elaboration, though it does not involve anything a computer scientist would recognise as an algorithm.

Turner (2008) notes that practices can be "underdetermined" and it may not always be obvious which practice is instantiated by a particular performance. In this instance, it is not necessarily clear how one could infallibly recognise a practice of "accepting or rejecting an inference", particularly if we assume a base language whose repertoire does not extend beyond assertions. Returning to example (1), but omitting the logical particle so:

1. (a) I am a bank employee going to work. (b) I shall wear a necktie.

there is clearly scope for ambiguity, or at least vagueness, over whether the speaker is expressing an inference from (a) to (b), or simply providing more information about his current activities. That is, the relation between (a) and (b) could be analysed in RST terms as Elaboration rather than, say, Volitional Cause (Mann and Thompson, 1987; Taboada and Mann, 2006). Scholman et al (2017) noted that there is substantial disagreement among annotators over whether implicit relations between text spans should be classed as "elaborative" or "argumentative", looking in particular at annotations of the Wall Street Journal corpus using the PDTB (Prasad et al., 2008) and RST (Carlson et al., 2003) frameworks. In what follows we will outline an alternative rational reconstruction of the introduction of conditional reasoning into a discursive practice, building on a basic practice which is taken to minimally include assertions, challenges and commands.

\subsection{Methodological issues with the LX programme}

One difficulty for Brandom's programme of logical expressivism is that it could only be conclusively verified by observing inferential practices before and after the introduction of logical vocabulary. However, the idea that this vocabulary is "introduced" into a linguistic practice which had previously lacked such terms is a fiction, or at least an unverifiable speculation. Logical expressivism therefore has to be interpreted as a claim that logical vocabulary allows us to codify practices which can be manifested in a language that has been stripped of such vocabulary. In this situation, it is hard to see how one could identify the "basic" or "core" practices as distinguished from practices that may 
have been altered in the light of reflections facilitated by logical vocabulary. Furthermore, Brandom acknowledges that

Once the logical vocabulary has been introduced, it may induce practitioners to alter their prior practice, in the light of what it now allows them to say about that practice.

(Brandom, 2009a, p. 354)

Macfarlane (2008) argues that the ability to algorithmically elaborate discursive practices is not itself one of the core abilities manifested in basic assertional practices, and that it involves other novel abilities such a syntactic ability to combine sentences using operators. Furthermore, I would argue that the proper use of conditionals assumes an ability to envisage and describe hypothetical/irrealis states of affairs, which is not needed for a basic assertional practice. A sequence $A$, so $B$ involves commitment to both $A$ and $B$, but If $A$ then $B$ on its own involves commitment to neither.

For the purposes of this paper, I will assume that the goal is to investigate conceptual dependencies between practices such as asserting, commanding and exhibiting conditional reasoning, and I will argue that a rational reconstruction of the genesis of the conditional locution can be achieved if asserting and commanding are given, but not on the basis of assertive practices alone. That is not necessarily to say that these practices can be observed as chronologically prior to conditional reasoning either in language evolution or acquisition, though it suggests interesting possibilities for applied research.

A further technical point: Weiss (2009) discusses the logical consequence relation defined in Brandom (2008) which is based on a primitive notion of incompatibility, and assumes that speakers are able to determine "a fully determinate incompatibility relation between arbitrary finite sets of sentences". He raises the issue that this may be beyond the reasoning capacities of speakers of the base language, but that the introduction of logical operators may enable them to "decide undetermined incompatibilty relations" (emphasis in original). It is not clear that Brandom satisfactorily addresses this specific point in his reply to Weiss (Brandom, 2009a), while as noted above Piwek (2011) shows that conservativity requires unbounded resources and processing time.

\subsection{Introducing "complex directives"}

It is a constant refrain in Brandom's work that language games (or autonomous discursive practices, ADPs) must include "practices of giving and asking for reasons, because assertions, the most basic kinds of sayings, must be capable of both serving as and standing in need of reasons " (Brandom, 2008, p. 43). (Although in fact Brandom's basic assertional practice does not appear to provide a means of asking for reasons, as noted above.) Another kind of saying or discursive practice which can lead to demands for reasons is giving commands or orders; thus it seems desirable that any practice which includes commands should also include assertions ${ }^{16}$. The MultiNLI corpus includes numerous examples where the premise consists of a command followed by an assertion which can be construed as immediately giving a reason to follow the command:

\section{Example 19}

(a) Walk through the gateway and you'll find yourself in an immense open space the largest temple courtyard in the country.

16. In fact it has been claimed that "commands" precede "assertions" in both the development and evolution of language (see e.g. Tomasello and Camaioni, 1997). 
(b) If you walk through the gate, you will be in the largest temple courtyard in the country.

Many of these kind of examples, of which there are several in the corpus, can be interpreted as "entailing" the first conjunct ${ }^{17}$, in contrast to some examples we considered above: the speaker of (19a) does appear to be advising the hearer to walk through the gateway. The second conjunct is arguably also entailed if we treat this as a kind of dynamic conjunction: the assertion is claimed to be correct or licit in the context created by executing the command. Note that adding commands to an assertional practice introduces the notion of a hypothetical (irrealis) state of affairs, since it is clearly desirable that we can envisage and reason about the expected consequences of following a command. The second conjunct thus has the dual role of describing the consequences of executing the command, and giving a reason to do so. Interpreting the sentence in this way thus involves conditional reasoning, although no explicit conditional construction is present.

These constructions are known in the literature as pseudo-imperatives (Fox, 2015), which have the sense of conditionals rather than actual commands or instructions. However, we can identify a subclass which have the force of genuine directives, as noted above: the speaker is in fact instructing or advising the hearer to do something. I will dub these cases complex directives, to be distinguished from pseudo-imperatives, and will suggest that they be treated as a basic form from which the latter derive - and, more speculatively, that they provide the essential ingredients for the conditional locution itself.

\subsection{A closer look at directives}

Before proceeding, it will be useful to operate with a finer-grained classification of directive speech acts (acts which strive to bring it about that another person does something), which will draw on the analysis of Rebecca Kukla and Mark Lance (Kukla and Lance, 2009, 2010; Lance and Kukla, 2013). Lance and Kukla propose a small number of assumptions which turn out to yield a fair amount of mileage:

- Terms like "imperative", "declarative" are pragmatic categories which do not necessarily have any systematic correspondence with what they call "surface grammar";

- Speech acts are treated as functions whose inputs and outputs are normative statuses;

- Inputs and outputs are classified as agent-neutral or agent-relative: for example a truth-claim will be agent-neutral since its truth or falsity holds (in principle) for everybody, while a directive has an agent-relative output which targets the addressee;

- Directives are subcategorised as prescriptives which articulate a pre-existing commitment, and imperative which assert some authority to instruct someone to fulfil a commitment. Imperatives can be distinguished as those which create a commitment (dubbed "constative") and those which articulate or ostend an existing commitment ("alethic").

I will make a further distinction between deontic and prudential practical commitments, i.e. commitments which arise from obligation and those which arise from self-interest.

With this terminology in place, Kukla and Lance's four ways of getting someone to do something (Kukla and Lance, 2009, pp. 105ff)consist of:

17. Assuming the permissive notion of "entailment" discussed above. 
1. Third person prescriptives, with agent-neutral input and both agent-relative and agent-neutral outputs, whose primary effect is to make a truth claim about a normative commitment, e.g. "Scott needs to lose weight";

2. Second person prescriptives, again with agent-neutral input and both agent-relative and agentneutral outputs, whose primary effect is to ostend or draw attention to a practical commitment: "You [Scott] need to lose weight";

3. Alethic imperatives, with agent-relative inputs and outputs, which not only ostend but seek to hold the addressee to a pre-existing norm: "Please lose weight"

4. Constative imperatives, with agent-relative inputs and outputs, which both create and seek to hold the addressee to a new practical commitment: "Move away from the vehicle", spoken by a police officer.

Prescriptives have both agent-relative and agent-neutral outputs since the claim they make is taken to be true for everyone, while the commitments referred to apply to a specific person or group. (That is, the speaker expects everyone to agree that Scott is overweight, but only Scott to embark on a weight-reduction programme.) Imperatives but not prescriptives have agent-relative inputs since some particular authority or status is required to issue a request or command. In this case, the speaker might be Scott's physician, partner or fitness trainer. In all of cases 1-3, the speaker might be guilty of rudeness but only in (3) would the utterance "misfire" pragmatically if the speaker lacks the appropriate normative relationship to Scott. Following this typology, we can identify examples from the corpus of complex directives where the (i) clause can be clearly labelled as prescriptive - despite having the "surface form" of an imperative - in that the speaker is not imposing any obligation on the hearer but is advising them of their best interests:

\section{Example 20}

(a) i. Take a left turn here on the B6318 and

ii. after $6 \mathrm{~km}$ (4 miles) you will see the sign for Birdoswald.

(b) If you travel for 6 kilometers after taking a left turn you'll see the sign for Birdoswald.

\section{Example 21}

(a) i. Click Nobel Prize Internet Archive Hayek Page, and

ii. you'll find yourself ...

(b) If you click the Nobel Prize Internet Archive...

A reminder: in each of examples (20-21) above, the (a) sentence is taken from the corpus and the (b) sentence is judged by a naive subject to be something that follows from it: so these complex directives are taken to imply conditionals. I argue that the (i) clauses meet Lance and Kukla's criteria for prescriptives rather than imperatives, despite sharing a grammatical form with imperatives, on the following grounds: 
- The speaker is not seeking to hold the hearer to a commitment, but is foregrounding and making a truth-claim about or attributing a prudential practical commitment. The speaker's utterance does not create this commitment, which is rather inherent in the addressee's particular situation. Assuming a context where in each case the hearer has a goal or practical commitment described by the (ii) clause, this goal commitment brings with it the prudential commitment identified in the (i) clause.

- The claim that the hearer has this commitment is true or false for everyone, thus agent-neutral, while the intended outputs include an acknowledgement on the part of the hearer that they have this commitment - thus agent-relative.

- While the prudential commitment identified in the (i) clauses is a material-inferential consequence of the goal commitment, the reverse is the case for entitlements: it is commitment to the performance of the action prescribed in (i) which will entitle Hearer to commit to the goal clause. If we accept the analysis that the prescriptive clause carries a truth-claim, I propose that this propositional claim can effectively be treated as the antecedent clause of a conditional.

In summary: knowledge of the hearer's goal entitles the speaker to articulate a prudential commitment on the hearer to take a particular action. Hearer's acknowledgement of this commitment will further commit them to achieving the state of affairs described in the (ii) clause. So the complex directive in the (a) sentences manifests the structure of a conditional as in the (b) examples.

If we compare the above examples with (22) and (23) below, we see that the imperative force is weakened and the conditional sense is foregrounded in the latter. Whereas both (20) and (21) give specific, targetted advice in a concrete context, (22) gives more generic advice while (23) is not at all advising the hearer to sneeze or catch a fever; the conditional sense has become primary.

\section{Example 22}

(a) i. Get individuals to invest their time and

ii. the funding will follow.

(b) If individuals will invest their time, funding will come along, too.

\section{Example 23}

(a) i. Sneeze in the middle of the night and

ii. your Edokko neighbor will demand the next morning that you take better care of yourself;

iii. stay home with a fever and

iv. she will be over by noon with a bowl of soup.

(b) If you develop a fever which results in you staying home, your Edokko neighbor will arrive by midday with soup.

This underscores Lance and Kukla's principle that surface grammar does not systematically predict pragmatic force: here we have three examples of ostensibly imperative constructions which function quite differently according to their context, semantic content and the nature of the micro-practice in which they are embedded. 


\subsection{Anaphoric dependencies in complex directives}

Examples (20-23) above all match the pattern Do $X$ and will $(\phi)$, as do most (though not all) examples in the Appendix. As argued above, the directive clause in these examples can be interpreted as a prescriptive, and so could also be expressed as You should do X... .

\section{Example 24}

You should take a left turn ... you will see the sign for Birdoswald.

The auxiliary will indicates a potential state of affairs which is a consequence of that postulated by a modal operator in the first clause, or by the imperative mood of a verb. This resembles the wellknown phenomenon of modal subordination Roberts (1989), which Kibble (1994) modelled with the aid of a co-indexing mechanism, analogous to that conventionally used to indicate anaphoric relationships between nominal expressions:

\section{Example 25}

It might ${ }^{\alpha}$ rain. You would $\alpha$ get wet.

In the cited work, the super- and subscripts partition the information state by picking out sets of possible worlds: in this example, the set of worlds where it rains is labelled with $\alpha$ and the second clause is evaluated against this restricted set. In the next section, I will argue that we can use a similar mechanism to partition an information state which comprises a commitment store, capturing the dependency between the prescriptive clause and the conjunct

\subsection{A dialogical account of discourse structure}

The effect of a complex directive is to utter a command, request or suggestion and immediately give some reason for executing it, as if anticipating a query or objection from the addressee. Thus they can be seen to encapsulate Brandom's Sellarsian notion of discourse as a game of giving and asking for reasons. This is in the spirit of Kibble (2006; 2007), which proposed that discourse structure could be analysed as the outcome of an "inner dialogue", where the speaker pre-empts or anticipates such demands for reasons. For instance, a dialogue like (26) from Kibble (2007) could be collapsed into a monologue (27) if the speaker anticipates their interlocutor's contributions at (b,d). The resulting monologue (27) has been marked up with RST relations (Mann and Thompson, 1987; Taboada and Mann, 2006):

\section{Example 26}

(a) A: You should take an umbrella.

(b) B: Why?

(c) A: It's going to rain.

(d) B: It doesn't look like rain. It's sunny.

(e) A: I heard it on the $B B C$. 


\section{Example 27}

\section{Motivate}

Nucleus You should take an umbrella

\section{Satellite}

\section{Evidence}

\section{Nucleus}

\section{Concession}

Nucleus It's going to rain

Satellite even though it looks sunny

Satellite I heard it on the BBC

We can construct a similar hypothetical dialogue which might underlie a complex directive such as (20), repeated with RST annotations as (29):

\section{Example 28}

(a) A: Take a left turn here on the B6318.

(b) B: Why?

(c) A: ... after $6 \mathrm{~km}$ (4 miles) you will see the sign for Birdoswald.

\section{Example 29 Motivate}

Nucleus Take a left turn ...

Satellite ... you will see the sign for Birdoswald

A plausible conjecture is that the pseudo-imperative form may have its origin in genuine (complex) directives, which sought to forestall the hearer's challenge or clarification request, and were subsequently generalised to conditional uses where the command is not separately entailed by the conjunction. So as noted above, a speaker of (30) is not advising their interlocutor to sneeze:

\section{Example 30}

Sneeze in the middle of the night and your Edokko neighbor will demand the next morning that you take better care of yourself...

Logical vocabulary makes this conditional sense explicit, and thus avoids commitment to the command on its own. So we can broadly trace this development in terms of the following augmentations to a purely assertional practice:

1. Introduce directives which have the effect of adding to the hearer's attributed commitments;

2. Introduce a practice of challenging directives, i.e. demanding reasons;

3. Introduce a practice of following directives with some justification, pre-empting challenges; 
4. Introduce logical vocabulary which expresses the conditional implied by complex directives;

5. Eventually the conditional sense becomes primary, and is read back into the original construction.

This will be spelled out in terms of schematic dialogue acts and commitment stores below. Note that although we have taken a different route than Brandom from a basic discursive practice to a more sophisticated one, the proposed analysis is within the spirit of his LX project, in that it claims to account for how we use more complex locutions to say what we are doing in the lower-level practices.

\section{Specifying dialogue acts}

The main aim of this section is to lay some foundations for implementable models of dialogue in which utterances are modelled as updates to an information state (IS) in the style of Traum et al. (1999), minimally sufficient to model the dialogical genesis of conditional locutions which is argued for in this paper. The framework presented here is adapted from that of Kibble (2007). The IS will keep track of interlocutors' deontic statuses, namely the relevant sets of commitments and entitlements acknowledged and attributed by discourse participants. We begin by outlining the structure of the information state and subsequently sketch the update effects of selected dialogue acts. A fully-fledged commitment store would keep track of each dialogue participant's attributions of everyone's commitments and entitlements, with self-attributions as acknowledgments of commitments. To keep things manageable within the scope of this paper, we will mostly restrict the discussion to second-person attributions of commitments.

\subsection{The information state as a commitment store}

Agents play one of three (dynamically assigned) roles at any given point in a dialogue: Speaker, Addressee (targeted by utterance), Hearer (not directly addressed).

1. For an agent $A_{i}$ to direct a claim $\phi$ towards an agent $A_{j}$ is to attribute to $A_{j}$ a particular deontic stance towards $\phi$.

2. The global information state CStore tracks deontic statuses for every participant $A_{i}$ and includes the following types of entries:

$\operatorname{Attr}\left(A_{i}, A_{j}, C(\operatorname{dox}(\phi)) A_{i}\right.$ attributes to $A_{j}$ a doxastic (propositional) commitment to $\phi$, a commitment to justify $\phi$ if challenged;

$\operatorname{Attr}\left(A_{i}, A_{j}, C(\operatorname{prac}(\phi)) A_{i}\right.$ attributes to $A_{j}$ a practical commitment to $\phi$, a commitment to bring it about or stit ${ }^{18}$ that $\phi$;

$\operatorname{Attr}\left(A_{i}, A_{j}, E(\operatorname{dox}(\phi)) A_{i}\right.$ attributes to $A_{j}$ the entitlement to make a doxastic (propositional) commitment to $\phi$;

$\operatorname{Attr}\left(A_{i}, A_{j}, E(\operatorname{prac}(\phi)) A_{i}\right.$ attributes to $A_{j}$ the entitlement to make a practical commitment to $\phi$.

18. Modelled on Belnap's (1990) "stit" or "see to it that" operator. 
Where $i=n$, the scoreboard includes agent $A_{n}$ 's self-attributed commitments or entitlements, the closest thing to private beliefs in this framework.

3. A partition PCStore tracks pending commitments which require acceptance by the targeted agent in order to become binding.

4. In order to capture the distinction between prescriptives and imperatives proper, we introduce a new facility for speakers to directly update hearers' practical commitments, if they have the appropriate authority:

$$
\begin{aligned}
& \operatorname{Add}\left(A_{i}, A_{j}, C(\operatorname{prac}(\phi)) A_{i} \text { bestows on } A_{j} \text { a practical commitment to } \phi ;\right. \\
& \operatorname{Attr}\left(A_{i}, A_{j}, E(\operatorname{prac}(\phi)) A_{i} \text { bestows on } A_{j}\right. \text { the entitlement to make a practical commitment } \\
& \quad \text { to } \phi .
\end{aligned}
$$

Part of the contents of the CStore is marked off as containing provisional or hypothetical commitments. For example, a practical commitment on the part of agent $A_{i}$ to bring it about that $\phi$ potentially leads to a doxastic commitment to $\phi$ once the action has succeeded. We will refer to these entities as dependent commitments, using a conventional super/subscript notation to indicate the dependency So if Rhoda says "Joe, you should wash the dishes" the CStore is updated with:

\section{$\left\{\operatorname{Attr}\left(R, J, C(\operatorname{prac}(\operatorname{clean}(\operatorname{dishes})))^{\alpha}\right), \operatorname{Attr}\left(R, J, C(\operatorname{dox}(\operatorname{clean}(\text { dishes })))_{\alpha}\right)\right\}$}

A directive act gives rise to two species of commitment: a primary, practical commitment to an action which is intended to bring about some state of affairs, and a dependent, doxastic commitment to this state of affairs holding once the action had been successfully performed.

\subsection{Complex directives and conditionals}

We propose that in the case of complex directives as discussed in section 4.3, conjoined phrases involving an auxiliary verb such as will can also be treated as giving rise to dependent commitments. A justification for this is that, as argued in section 4.5 above, the auxiliary will can have a quasianaphoric function, referring back to a previous operator as in cases of modal subordination such as "Joe, you should ${ }^{\alpha}$ wash the dishes and I will $\alpha$ dry". In this example, Rhoda self-attributes a practical commitment to drying the dishes in the eventuality that Joe washes them.

Consider again example (19), slightly simplified:

Example 31 "Walk through the gateway and you will find yourself in the largest temple courtyard in the country."

The CStore is updated with:

$$
\begin{aligned}
& \left\{\operatorname{Attr}\left(\operatorname{Sp}, H, C(\operatorname{prac}(\operatorname{through}(H, \text { gateway })))^{\alpha}\right),\right. \\
& \operatorname{Attr}\left(\operatorname{Sp}, H, C(\operatorname{dox}(\operatorname{through}(H, \text { gateway })))_{\alpha}^{\beta}\right), \\
& \left.\operatorname{Attr}\left(\operatorname{Sp}, H, C(\operatorname{dox}(\operatorname{in}(H, \text { courtyard })))_{\beta}\right)\right\}
\end{aligned}
$$

We now have two consecutive instances of dependent commitments: a practical commitment to walking through the doorway gives rise to a (future) doxastic commitment of being the other side of the doorway; and this doxastic commitment triggers a commitment to the claim that one is in 
the temple courtyard. Now, the validity of this dependency clearly does not depend on whether one actually walks through the doorway. Introducing a conditional locution allows us to express the dependency without requiring the initial practical commitment:

Example 32 "If you walk through the gate, you will be in the largest temple courtyard in the country."

Note that this formulation is considered by the subject to be entailed by (31), and does not convey any more information than was present in that example: in fact it conveys less, as it does not impute any concrete commitments to the addressee. How to handle this in terms of updating the CStore? One approach is to "offer" rather than attributing a practical commitment, which the addressee may choose to accept or not: this enables the speaker to indicate dependent commitments without assuming or requiring any initial commitment from the hearer. This is modelled by adding the relevant attributions to the PCStore rather than the primary CStore:

$\left\{\operatorname{Attr}\left(\operatorname{Sp}, H, C(\operatorname{prac}(\text { through }(H, \text { gateway })))^{\alpha}\right)\right.$,

$\operatorname{Attr}\left(\operatorname{Sp}, H, C(\operatorname{dox}(\operatorname{through}(H, \text { gateway })))_{\alpha}^{\beta}\right)$,

$\left.\operatorname{Attr}\left(\operatorname{Sp}, H, C(\operatorname{dox}(\operatorname{in}(H, \text { courtyard })))_{\beta}\right)\right\}$

This approach is suggested by Habermas's notion of a dialogue act offer (Sprechaktangebot, Habermas (2000); Kreutel and Matheson (2002)) though our use of the term is somewhat different from his. The point here is that the hearer is not considered to be committed to the action in question, but it can be read off from the CStore that if they do so, the specified consequence will follow.

At this point we have outlined how a complex directive within a cooperative goal-oriented dialogue can be interpreted and expressed as entailing a conditional statement, with some modification to the assumed underlying CStore updates. Suppose we now re-analyse the original directive as involving an offer rather than an attribution of a practical commitment, in line with Brandom's observation:

Once the logical vocabulary has been introduced, it may induce practitioners to alter their prior practice, in the light of what it now allows them to say about that practice.

(Brandom, 2009a, p. 354)

The effect is that the initial practical commitment is now hypothesised rather than attributed, yielding a conditional reading of the directive. This seems to apply more naturally to what I call the "generic" and "counterfactual" variants of complex directives represented by (33) and (34) respectively, which are primarily understood as conditional statements with no commitment required to the actions indicated in the directive clauses.

\section{Example 33}

(a) Get individuals to invest their time and the funding will follow.

(b) If individuals will invest their time, funding will come along, too.

\section{Example 34}

(a) Sneeze in the middle of the night and your Edokko neighbor will demand the next morning that you take better care of yourself; stay home with a fever and she will be over by noon with a bowl of soup. 
(b) If you develop a fever which results in you staying home, your Edokko neighbor will arrive by midday with soup.

\subsection{Dialogue acts and updates}

In what follows $\mathbf{S p}=$ speaker, $\mathbf{A d}=$ Addressee, $\mathbf{H s}=$ Hearers

$\operatorname{assert}(\mathbf{S p}, \phi$, Ad, Hs) publicly undertake commitment to justify a propositional claim $\phi$.

Updates Add to CStore:

$\operatorname{Attr}(S p, S p, C(d o x(\phi))$ Sp self-attributes a doxastic (propositional) commitment to $\phi$, a commitment to justify $\phi$ if challenged;

$\operatorname{Attr}(S p, S p, E(\operatorname{dox}(\phi))$ Sp self-attributes the entitlement to make a doxastic (propositional) commitment to $\phi$;

$\operatorname{Attr}(S p, H, C(\operatorname{dox}(\phi)) \mathrm{Sp}$ attributes to $\mathrm{H}$ a doxastic (propositional) commitment to $\phi$,

$\operatorname{Attr}(S p, H, E(\operatorname{dox}(\phi))$ Sp attributes to $\mathrm{H}$ the entitlement to make a doxastic (propositional) commitment to $\phi$;

prescribe(Sp, $\phi$, Ad, Hs) publicly attribute to $A d$ commitment to bring it about that $\phi$.

Updates Add to CStore:

$\operatorname{Attr}\left(S p, H, C(\operatorname{prac}(\phi))^{i} \mathrm{Sp}\right.$ attributes to $\mathrm{H}$ a practical commitment to $\phi$,

$\operatorname{Attr}\left(S p, H, C(\operatorname{dox}(\phi))_{i}\right.$ Sp attributes to $\mathrm{H}$ a dependent doxastic commitment to $\phi$,

$\operatorname{Attr}(S p, H, E(\operatorname{prac}(\phi))$ Sp attributes to $\mathrm{H}$ the entitlement to make a practical commitment to $\phi$;

command(Sp, $\phi$, Ad, Hs) S publicly attributes to and bestows on $A d$ commitment to bring it about that $\phi$.

Updates Add to CStore:

$\operatorname{Attr}\left(S p, H, C(\operatorname{prac}(\phi))^{i} \mathrm{Sp}\right.$ attributes to $\mathrm{H}$ a practical commitment to $\phi$,

$\operatorname{Attr}\left(S p, H, C(\operatorname{dox}(\phi))_{i}\right.$ Sp attributes to $\mathrm{H}$ a dependent doxastic commitment to $\phi$,

$\operatorname{Attr}(S p, H, E(\operatorname{prac}(\phi))$ Sp attributes to $\mathrm{H}$ the entitlement to make a practical commitment to $\phi$;

$\operatorname{Add}(S p, H, C(\operatorname{prac}(\phi)) \mathrm{Sp}$ bestows on $\mathrm{H}$ a practical commitment to $\phi$,

$\operatorname{Add}(S p, H, E(\operatorname{prac}(\phi))$ Sp bestows on $\mathrm{H}$ the entitlement to make a practical commitment to $\phi$;

$\operatorname{propose}(\mathbf{S p}, \phi, \mathbf{A d}, \mathbf{H s})$ publicly offer to $A d$ commitment to bring it about that $\phi$.

Updates Add to PCStore (pending commitments):

$\operatorname{Attr}(S p, H, C(\operatorname{prac}(\phi)) \mathrm{Sp}$ attributes to $\mathrm{H}$ a practical commitment to $\phi$,

$\operatorname{Attr}\left(S p, H, C(\operatorname{dox}(\phi))_{i}\right.$ Sp attributes to $\mathrm{H}$ a dependent doxastic commitment to $\phi$, 
$\operatorname{Attr}(S p, H, E(\operatorname{prac}(\phi))$ Sp attributes to $\mathrm{H}$ the entitlement to make a practical commitment to $\phi$;

\section{Complex acts and dependent commitments}

$\operatorname{act}_{1}(\mathbf{S p}, \phi, \mathbf{A d}, \mathbf{H s})^{i} \wedge \mathbf{a c t}_{2}(\mathbf{S p}, \phi, \mathbf{A d}, \mathbf{H s})_{i}$

If the connective $\wedge$ is interpreted as a dynamic conjunction:

Commitment store updates arising from act $_{1}$ are stored in a partition labelled $i$;

Commitment store updates arising from act $_{2}$ only take effect if those in partition $i$ are discharged.

\section{What kind of practices are "discursive practices"?}

This paper has argued for a treatment of various linguistic phenomena in terms of evolving discursive practices, and in particular has sought to show that the conditional locution could plausibly have developed out of speech acts embedded in goal-directed cooperative dialogue. We have been using the term "discursive practice" as if it were clearly understood, though in fact it is not in widespread use among semanticists and pragmatists in the Anglo-American tradition and Brandom does not give any detailed account of what is meant by practices (or the studiedly non-committal term "practices-or-abilities" which occurs throughout BSD). To help get a better grip on how linguistic interaction can be characterised in terms of social practice, this section explores similarities and differences between Brandom's approach and that of the French sociologist and anthropologist Pierre Bourdieu (following on from (Kibble, 2014)), noting some shared connections with the later Wittgenstein. Both Brandom and Bourdieu are concerned with how practical knowledge can be articulated and become a subject for discussion, as well as with processes of elaborating basic practices into more sophisticated ones. Bourdieu's highly influential work on the logic of practice (Bourdieu, 1977, 1991) focusses on a notion of practices as the fundamental level of description of the behaviour of individuals in social contexts. Rouse's (2007a) survey of practice theories places Bourdieu and Brandom in distinct camps: according to him, Bourdieu is one of the theorists who "make central to their discussion of practices those aspects of human activity which they regard as tacit and perhaps inexpressible in language", while Brandom belongs to the party who "treat language itself (or 'discursive practice') as a paradigmatic application of practice talk". Further, a practice for Bourdieu may consist of a frequently repeated performance or sequence of actions, while for Brandom it is essentially normative, something which may be done correctly or incorrectly according to communally accepted standards (Rouse, 2007b). A close reading of two key texts (Bourdieu, 1977; Brandom, 2008) suggests that the two scholars have a number of concerns in common:

1. Commitments and objective intentions. For Brandom, to make an assertion is to take on a commitment to justify that assertion if challenged; commitments are a matter of social, normative status rather than psychological states, with practical commitments taking the place of intentions. Thus an agent may be assessed by others as being committed to propositions which are entailed by their overt commitments, whether or not they acknowledge such commitments. Levesque (1984) sought to capture this distinction with a "logic of implicit and explicit belief". There is an echo here of Bourdieu, who speaks of agents having "objective 
intentions" which always outrun "conscious intentions" since actions are "the product of a modus operandi" over which the agent has no "conscious mastery" (Bourdieu, 1977, p. 79).

2. Communication as challenge and riposte. Bourdieu (1977, p. 14) claims that this is "the limit towards which every act of communication tends" and appears to see every social encounter as a potential occasion for expressing dominance or deference, while Brandom's notion of autonomous discursive practice requires a speech act of challenging entitlement to propositional commitments (Kibble, 2004, 2006; Wanderer, 2009; Brandom, 2009b). In the works we are focussing on in this paper Brandom tends to abstract away from questions of power imbalance among participants in a dialogue and to assume something like a Habermasian ideal speech situation (Habermas, 1995), though in other work he shows an alertness towards the "power-laden asymmetric recognitive relations that articulate various modern social practices" (Brandom, 2015) .

3. Background knowledge in the form of habitus or material inference. For Bourdieu, individual practices are both constrained by and contribute to the habitus, defined as "Systems of durable, transposable dispositions ... Objectively 'regulated and regular without being in any way the product of obedience to rules ..." (quoted by Grenfell (2011)) The reader may be reminded of Foucault's discursive formations (Foucault, 1972). For Brandom, command of a language involves the practical ability to deploy a particular vocabulary, including the ability to make and endorse inferences such as that from This coat is scarlet to This coat is red, or from It is raining to The streets will be wet.

4. Generative schemes and algorithmic elaboration. Both authors outline ways in which basic or core practices can be combined to generate new practices appropriate to particular situations. For example, Bourdieu discusses how the gravity of a theft and the concomitant severity of punishment are determined among the Kabyle of Algeria on the basis of "a small number of schemes that are continually applied in all domains of practice" (Bourdieu, 1977), while Brandom as we have seen argues that certain "primitive practices-or-abilities" can be algorithmically elaborated into more complex ones by procedures equivalent to transducing automata (Brandom, 2008).

5. Explication. Both authors are concerned with the issue of codifying or explicating practices. Bourdieu argues that "practice has a logic which is not that of logic" while Brandom (Brandom, 2008, p.33) claims to offer a "logic of practical abilities". However, they differ over the extent to which practices can be made fully explicit: Bourdieu maintains that clusters of practices cannot always be explicitly codified without distortion or logical contradiction while Brandom is generally more optimistic, maintaining that logical vocabulary (such as conditional connectives) serves to make explicit inferential moves which are already implicit in any autonomous discursive practice that lacks this vocabulary (Weiss, 2009; Brandom, 2009a).

6. Both situate themselves in relation to the later Wittgenstein, particularly the sections of the Philosophical Investigations on rule following. Bourdieu (1977, p. 29) quotes with approval Wittgenstein's remarks that someone who appears to be acting in a predictable, rule-governed manner might be unable to expound any rule they are deliberately following, and argues that to consider a regularity in behaviour as evidence of a consciously propounded ruling or 
unconscious regulating is "to slip from the model of reality to the reality of the model". This anticipates Brandom's Wittgenstein-inspired critique of regulism and regularism, the notions that social norms are to be respectively identified with explicit rules or statistical regularities (Brandom, 1994).

Rouse (2007a) identifies the role of language as a contentious issue in practice theory, and argues both that "to use and respond to words and sentences as semantically significant is to engage in discursive practice" and that discursive and non-discursive practices are ultimately inseparable. Bourdieu (1991) develops a notion of "symbolic power", according to which the meanings of utterances and the efficacy of speech acts derives from the "social power" of speakers (Leezenberg, 2013). Brandom takes a more nuanced approach, seeking to show how semantic meanings can be grounded in social practices of "normative pragmatics", without the requirement of any explanatory role for semantic or intentional concepts. As we have seen, his approach involves a somewhat rarefied, abstract and irreducably normative account of what constitutes a "practice": in particular he tends to disregard questions of an imbalance of power among discourse participants, though Rouse (1994; 2002) contends that Brandom's framework is quite compatible with Foucault's and other contemporary accounts of interpersonal power.

Bourdieu problematises the explication of practices on two scores:

1. Attempts to collate and set down on paper various collections of practices, as for example in the different ways subjects observe the agrarian calendar, can lead to distortion or incoherence: features which are "compatible practically" may turn out to be "logically contradictory" (Bourdieu, 1977, p. 107). That is, invidual subjects may pursue practices that do not interfere with each other, but attempts to codify and harmonise their combined implicit knowledge may show up inconsistencies. This objection can be summed up as "practice has a logic which is not that of logic".

2. Once a practice has been codified and commonly agreed, reflection on the practice may lead agents to go back and revise it: explication is not a one-way street (Bourdieu, 1977, p. 20).

Brandom seems to be more optimistic on point (1): he argues that logical vocabulary must be "semantically transparent" and "inferentially conservative" with respect to material inferences that can be exhibited in the base language. However, he seems to come closer to Bourdieu's stance on point (2), acknowledging that

Once the logical vocabulary has been introduced, it may induce practitioners to alter their prior practice, in the light of what it now allows them to say about that practice. (Brandom, 2009a, p. 354)

This does in fact seem quite consonant with Bourdieu's notion of "the dialectic between the schemes immanent in practice and the norms produced by reflection on practices" (Bourdieu, 1977, p. 20); both authors appear to be in agreement that explication of practices is not just a one-way process but can feed back into modification of those practices. This may well be what has happened with pseudo-imperatives as discussed in the previous section: the introduction of conditional vocabulary leads to a re-interpretation of complex directives, foregrounding the implicit conditional sense and weakening the actual directive force. This may also be contrasted with Lance and Kremer's (1994) objection that the role of logic is purely normative, setting standards for rational argumentative 
discourse, and should not be identified with an abstraction from actual discursive practice as it is possible for an entire speech community to reason incorrectly. Their approach still seems to be faced with the question of what the sources of normativity actually consist in, if not some form of mathematical platonism.

As noted at various points above, Brandom's framework appears in places to tacitly rely on unlimited cognitive resources, as in the ability to quantify across all possible contexts or to maintain conservativity of inference following the introduction of logical operators. This seems at odds with a practice-theoretic orientation, which is rather concerned with finite, bounded performances. In fact in BSD Brandom appears to move towards a more "cognitivist" position, using the studiedly non-committal term "practices or abilities" throughout and declaring restrictions on inferential operations to be "psychological": the framework starts to look more like a "competence" theory which abstracts away from the actual capabilities of embodied cognitive agents.

\section{Conclusion and Future Work}

This paper has considered Brandom's expressivist programme in some detail, against the background of Bourdieu's practice theory and in confrontation with empirical data which attest to the actual use of logical connectives in everyday language, and concluded that it remains unproven. We have proposed a re-orientation of Brandom's normative pragmatics which problematises the notion of assertion as an autonomous discursive practice, and outlines a speculative origin story for conditionals as a routinisation of a family of micro-practices. As noted earlier, the goal was to investigate conceptual dependencies between practices such as asserting, commanding and exhibiting conditional reasoning, and we have argued that a rational reconstruction of the genesis of the conditional locution can be achieved if asserting and commanding are given, but not on the basis of assertive practices alone. That is not necessarily to say that these practices can be observed as chronologically prior to conditional reasoning either in language evolution or acquisition, though it suggests interesting possibilities for applied research. We have made a case that even "logical" vocabulary items do not have invariant meanings or inferential force independent of context, but function differently according to the particular practice within which they are employed; this paper has discussed assertive, imperative and prescriptive practices, as well as cooperative dialogue involving conditional reasoning. An implication of this thesis is that one cannot speak of arguments expressed in natural language as being formally valid, except perhaps in a regimented controlled language of the kind one finds in logic textbooks. This need not be such an alarming conclusion if we consider that much everyday inference lacks formal validity: examples include Affirming the Consequent in the guise of abduction, and Argument from Authority which is surely unproblematic in many everyday situations. Clearly much work remains to be done in fleshing out the details of this proposal, and extending this style of analysis to the behaviour of other so-called logical connectives which poses problems for a classic truth-functional analysis. We have also shown how the MultiNLI corpus provides a valuable resource for investigating "natural inference" as practised in everyday language, which may help to clarify the role of "material inference" in a practice-theoretic framework. Brandom's framework turns out to provide a fruitful basis for investigating discursive practices in which speech and action are closely interleaved. There has been relatively little work in computational modelling of practice theories: Narasimhan et al. (2017) report on a "conceptualisation" of social practice theory using agent-based modelling, but note that this requires addressing some key questions which are not resolved in the literature. Future work will aim to build on this 
conceptualisation to model particular characteristics of discursive practice, and will engage with related work in the philosophy of language (e.g. Williamson, 1996) and other areas of study which bear on some of the problems addressed in this paper, including Conversational Analysis (Drew, 2005) and linear logic (Porello et al., 2009),

A final point: Brandom's inferentialism was worked out in confrontation with the then dominant frameworks of formal semantics, and is largely intended to tackle the kind of problems formal semanticists thought were important. The important new paradigm of distributional semantics (DS, Boleda and Herbelot (2016)), like Brandom's inferentialism, has also been claimed to be inspired by Wittgenstein, though philosophically inclined commentators have generally disregarded this work as it is somewhat outside their purview. It remains to be seen whether DS will fatally undermine inferentialism or, on the other hand, may prove to be complementary. For example, Kremer's accusation of circularity in the definition of syntactic categories might be sidestepped if we begin by using machine learning to induce categories from corpus data. It is ironic that both DS and inferentialism claim inspiration from Wittgenstein given Brandom's skepticism about quantitative methods: his critique of "regularism", which essentially identifies norms with statistical regularities, is that it fails to distinguish between what is usually done and what ought to be done ${ }^{19}$.

\section{Acknowledgements}

Thanks to Ken Turner and the Dialogue and Discourse reviewers for detailed comments on previous drafts of this paper, and to Paul Piwek for stimulating conversations over the years on these and related matters.

\section{Appendix A. Examples from MultiNLI corpus}

1. (a) Get individuals to invest their time and the funding will follow.

(b) If individuals will invest their time, funding will come along, too.

2. (a) Do begin again, and Prudie predicts 1999 will be your year.

(b) If you start over again, Prudie insists that the year 1999 will be a lucky one for you.

3. (a) Lucinda- Write a song about Pale Fire and he's yours!

(b) If you write a song about Pale Fire, he's yours.

4. (a) Ignore the proprieties or offend the pride of an Edokko and he will let you know about it, in no uncertain terms; respect his sense of values and you make a friend for life.

(b) If you offend an Edokko, he will let you know that he is upset at you.

5. (a) just stir that in and you've got a very colorful side another dish

(b) If you want a colorful side dish, then stir that in.

6. (a) Subtract the shock value, and what you have here is the salon painting of the 1990s.

(b) If you minus the shock value, you have a salon painting from the 1990s.

19. The tension between distributionalism and normativity is discussed at length by Lücking et al. (2019) 
7. (a) Follow the N-332 a little farther to Vera, then take the road to Garrucha and the coast (the N-340 continues inland until Almeraa).

(b) If you follow the N-332 a little longer, it will lead you to a road you can take to Garrucha and the coast.

8. (a) Sneeze in the middle of the night and your Edokko neighbor will demand the next morning that you take better care of yourself; stay home with a fever and she will be over by noon with a bowl of soup.

(b) If you develop a fever which results in you staying home, your Edokko neighbor will arrive by midday with soup.

9. (a) yeah scrape it and paint it put primer on it then paint it don't put paint over else it'll just continue rusting under it yeah.

(b) If you paint over it without scraping and putting primer, it will continue rusting underneath.

10. (a) "Give them something to watch and remember and they will forget what you dont want them to see," said Jon.

(b) If you offer them an alternative, they will not remember anything else.

11. (a) Take a left turn here on the B6318 and after $6 \mathrm{~km}$ (4 miles) you will see the sign for Birdoswald.

(b) If you travel for 6 kilometers after taking a left turn you'll see the sign for Birdoswald.

12. (a) As for people you deal with regularly (like doormen, since you're a Manhattanite), grease their palms once every several encounters, or else you'll go crazy and broke.

(b) If you don't grease the palms of people you deal with, you'll go crazy and broke.

13. (a) Walk through the gateway and you'll find yourself in an immense open space the largest temple courtyard in the country.

(b) If you walk through the gate, you will be in the largest temple courtyard in the country.

14. (a) As I said, get me to Sydney, get me to the opening ceremony and the torch and the hymns, and I'll be fine.

(b) If i'm at the opening ceremony in Sydney, I'll be fine.

15. (a) "Get the properties and you can go right ahead!" Dr. Hall found his voice.

(b) If the person Dr. Hall is speaking to gets what they need they can go right ahead.

16. (a) Click Nobel Prize Internet Archive Hayek Page, and you'll find yourself ...

(b) If you click the Nobel Prize Internet Archive ...

17. (a) Respond in kind and you'll soon feel at home.

(b) If you treat them similarly you'll feel right at home in no time.

18. (a) Pay us for that with your service, and that new life will be truly precious. 
(b) If they help the others with their work, they will be much better in their life.

19. (a) Someone once said, "Get a job you love, and you'll never work a day in your life", Zucker said.

(b) If you like what you do, you'll never think of it as a job.

\section{References}

Kingsley Amis. The King's English: a guide to modern usage. Macmillan, 1999.

Laurie Bauer and Elizaveta Tarasova. The meaning link in nominal compounds. SKASE Journal of Theoretical Linguistics, 10(3), 2013.

Nuel Belnap. Declaratives are not enough. Philosophical Studies: An International Journal for Philosophy in the Analytic Tradition, 59(1):1-30, 1990.

Emily Bender and Alexander Koller. Climbing towards NLU: On meaning, form, and understanding in the age of data. In Proceedings of the 58th Annual Conference of the Association for Computational Linguistics. Association for Computational Linguistics, 2020.

Gemma Boleda and Aurélie Herbelot. Formal distributional semantics: Introduction to the special issue. Computational Linguistics, 24:619-635, 2016.

Pierre Bourdieu. Outline of a Theory of Practice. Cambridge University Press, Cambridge, 1977. Translated by R. Nice.

Pierre Bourdieu. Language and Symbolic Power. Polity Press, Cambridge, 1991. Translated by G. Raymond and M. Adamson, edited John B. Thompson.

Samuel R. Bowman, Gabor Angeli, Christopher Potts, and Christopher D. Manning. A large annotated corpus for learning natural language inference. In Proceedings of the 2015 Conference on Empirical Methods in Natural Language Processing (EMNLP). Association for Computational Linguistics, 2015.

Robert Brandom. Asserting. Noûs, pages 637-650, 1983.

Robert Brandom. Making It Explicit: Reasoning, Representing, and Discursive Commitment. Harvard University Press, Cambridge, MA, 1994.

Robert Brandom. Articulating Reasons: An Introduction to Inferentialism. Harvard University Press, Cambridge, MA, 2000.

Robert Brandom. Between Saying and Doing: Towards an Analytic Pragmatism. Oxford University Press, Oxford, 2008.

Robert Brandom. Reply to Weiss. In B. Weiss and J. Wanderer, editors, Reading Brandom: On Making it Explicit, pages 353-356. Routledge, London and New York, 2009a.

Robert Brandom. Reply to Wanderer. In B. Weiss and J. Wanderer, editors, Reading Brandom: On Making it Explicit, page 315. Routledge, London and New York, 2009b. 
Robert Brandom. Towards reconciling two heroes: Habermas and Hegel. Argumenta, page 29, 2015.

Lynn Carlson, Daniel Marcu, and Mary Ellen Okurowski. Building a discourse-tagged corpus in the framework of rhetorical structure theory. In Current and new directions in discourse and dialogue, pages 85-112. Springer, 2003.

Rudolf Carnap. Meaning postulates. Philosophical studies, 3(5):65-73, 1952.

Stephen Clark. Vector space models of lexical meaning. In Handbook of Contemporary Semantic Theory, Second Edition, pages 493-522. Wiley, 2015.

Paul Drew. Conversation analysis. In Handbook of language and social interaction, pages 71-102. 2005.

Michel Foucault. The archaeology of knowledge Routledge. Routledge, 1972. Translated by XXX.

Chris Fox. The Semantics of Imperatives. Handbook of Contemporary Semantic Theory, Second Edition, pages 314-342, 2015.

Jonathan Ginzburg. Questions. Oxford Bibliographies in Linguistics, 2017. doi: 10.1093/obo/ 9780199772810-0206. URL https: / / www . oxfordbibliographies.com.

Michael Grenfell. Bourdieu: A theory of practice. In Michael Grenfell, editor, Bourdieu, Language and Linguistics, pages 7-34. Continuum, London and New York, 2011.

Paul Grice. Meaning. Philosophical Review, 67:377-388, 1957. Reprinted in Semantics, edited by D. D. Steinberg \& L. A. Jakobovits (1971), Cambridge University Press, pages 53-59.

Jürgen Habermas. Wahrheitstheorien (1972). In Vorstudien und Ergänzungen zur Theorie des kommunikativen Handelns. Suhrkamp, 1995.

Jürgen Habermas. Comments on John Searle: Meaning, communication and representation. In Maeve Cooke, editor, On the pragmatics of communication. MIT press, 2000.

Charles Hamblin. Fallacies. Methuen, London, 1970.

Ray Jennings. The meaning of connectives. In Steven Davis and Brendan S Gillon, editors, Semantics: a reader. Oxford University Press, 2004.

Hans Kamp. Two theories about adjectives. In Steven Davis and Brendan S Gillon, editors, Semantics: a reader. Oxford University Press, 2004. Originally published in Ed Keenan (ed.), Formal Semantics of Natural Language, CUP, 1975.

Rodger Kibble. Dynamics of epistemic modality and anaphora. In Proceedings of the International Workshop on Computational Semantics, 1994.

Rodger Kibble. Elements of a social semantics for argumentative dialogue. In Proceedings of the Fourth Workshop on Computational Modelling of Natural Argumentation, pages 25-28, 2004.

Rodger Kibble. Reasoning about propositional commitments in dialogue. Research on language \& computation, 4(2):179-202, 2006. 
Rodger Kibble. Generating coherence relations via internal argumentation. Journal of Logic, Language and Information, 16(4):387-402, 2007.

Rodger Kibble. Discourse as Practice: from Bourdieu to Brandom. In Proceedings of the 50th AISB Convention, Goldsmiths, University of London, 2014.

Michael Kremer. Representation or inference: must we choose? should we? In Reading Brandom: On Making It Explicit. Routledge, 2009.

Jörn Kreutel and Colin Matheson. From dialogue acts to dialogue act offers: Building discourse structure as an argumentative process. In Proceedings of EDILOG, page 86, 2002.

Rebecca Kukla and Mark Lance. "Yo!" and "Lo!": The Pragmatic Topography of the Space of Reasons. Harvard University Press, 2009.

Rebecca Kukla and Mark Lance. Perception, language, and the first person. In Reading Brandom, pages 125-138. Routledge, 2010.

George Lakoff. Linguistics and natural logic. Synthese, 22(1-2):151-271, 1970.

Mark Lance. The logical structure of linguistic commitment III: Brandomian scorekeeping and incompatibility. Journal of Philosophical Logic, 30:439 - 64, 2001.

Mark Lance and Philip Kremer. The logical structure of linguistic commitment I: Four systems of non-relevant commitment entailment. Journal of Philosophical Logic, 23:369 - 400, 1994.

Mark Lance and Philip Kremer. The logical structure of linguistic commitment II: Systems of relevant commitment entailment. Journal of Philosophical Logic, 25:425 - 49, 1996.

Mark Lance and Rebecca Kukla. Leave the gun; take the cannoli! the pragmatic topography of second-person calls. Ethics, 123(3):456-478, 2013.

Michiel Leezenberg. Power in speech actions. In arina. Sbisa and Ken Turner, editors, Pragmatics of Speech Actions, pages 287-213. De Gruyter Mouton, Berlin/Boston, 2013.

Hector Levesque. A logic of implicit and explicit belief. In AAAI, pages 198-202, 1984.

Judith Levi. The syntax and semantics of complex nominals. Academic Press, 1978.

Ronald Loeffler. Brandom. Polity, 2018.

Andy Lücking, Robin Cooper, Staffan Larsson, and Jonathan Ginzburg. Distribution is not enough: going firther. In Proceedings of the Sixth Workshop on Natural Language and Computer Science, pages 1-10, 2019.

John MacFarlane. Brandom's demarcation of logic. Philosophical Topics, 36(2):55-62, 2008.

William Mann and Sandra Thompson. Rhetorical structure theory: A theory of text organization. Technical Report ISI/RS-87-190, Information Sciences Institute, 1987.

Colin Matheson, Massimo Poesio, and David Traum. Modelling grounding and discourse obligations using update rules. In Proceedings of NAACL 2000, pages 1 - 8, 2000. 
Kavin Narasimhan, Thomas Roberts, Maria Xenitidou, and Nigel Gilbert. Using ABM to clarify and refine social practice theory. In Advances in Social Simulation 2015, pages 307-319. Springer, 2017.

Paul Piwek. Dialogue structure and logical expressivism. Synthese, 183(1):33-58, 2011.

Paul Piwek. Towards a computational account of inferentialist meaning. In Proceedings of AISB 2014, 2014.

Daniele Porello et al. Logic and pragmatics: linear logic for inferential practice. TAP-2009 Towards an Analytic Pragmatism, page 69, 2009.

Roland Posner. Semantics and pragmatics of sentence connectives in natural language. In Steven Davis and Brendan S Gillon, editors, Semantics: a reader. Oxford University Press, 2004. Originally published in Speech act theory and pragmatics, Springer, 1980.

Rashmi Prasad, Nikhil Dinesh, Alan Lee, Eleni Miltsakaki, Livio Robaldo, Aravind Joshi, and Bonnie Webber. The penn discourse treebank 2.0. In Nicoletta Calzolari (Conference Chair), Khalid Choukri, Bente Maegaard, Joseph Mariani, Jan Odijk, Stelios Piperidis, and Daniel Tapias, editors, Proceedings of the Sixth International Conference on Language Resources and Evaluation (LREC'08), Marrakech, Morocco, may 2008. European Language Resources Association (ELRA).

Craige Roberts. Modal subordination and pronominal anaphora in discourse. Linguistics and philosophy, 12(6):683-721, 1989.

Joseph Rouse. Power/knowledge. The Cambridge Companion to Foucault, 2, 1994.

Joseph Rouse. How scientific practices matter: Reclaiming philosophical naturalism. University of Chicago Press, 2002.

Joseph Rouse. Practice theory. Division I Faculty Publications. Paper 43, 2007a. http://wesscholar.wesleyan.edu/div1facpubs/43.

Joseph Rouse. Social practices and normativity. Division I Faculty Publications. Paper 44, 2007b. http://wesscholar.wesleyan.edu/div1facpubs/44.

Merel Cleo Johanna Scholman and Vera Demberg. Examples and specifications that prove a point: Identifying elaborative and argumentative discourse relations. Dialogue \& Discourse, 8(2):5683, 2017.

John Searle. Speech Acts: An Essay in the Philosophy of Language. Cambridge University Press, Cambridge, London, 1969.

Munindar Singh. A social semantics for agent communication languages. In Issues in Agent Communication, pages 31-45, 2000.

Maite Taboada and William Mann. Rhetorical structure theory: looking back and moving ahead. Discourse Studies, 8(3), 2006. 
Michael Tomasello and Luigia Camaioni. A comparison of the gestural communication of apes and human infants. Human Development, 40(1):7-24, 1997.

David Traum, Johan Bos, Robin Cooper, Staffan Larsson, Ian Lewin, Colin Matheson, and Massimo Poesio. A model of dialogue moves and information state revision. Technical report, Gothenburg University, Department of Linguistics; University of Edinburgh, Centre for Cognitive Science and Language Technology Group, Human Communication Research Centre; Universität des Saarlandes, Department of Computational Linguistics; SRI Cambridge; Xerox Research Centre Europe, 1999.

Giacomo Turbanti. Robert Brandom's Normative Inferentialism, volume 280. John Benjamins Publishing Company, 2017.

Stephen Turner. Practices as the new fundamental social formation in the knowledge society. Druzboslovne razprave, XXIV(59):49-64, 2008.

Johan van Benthem. A brief history of natural logic. 2007. ILLC, Universiteit van Amsterdam.

Douglas Walton and Eric Krabbe. Commitment in dialogue: basic concepts of interpersonal reasoning. SUNY series in logic and language. State University of New York Press, 1995.

Jeremy Wanderer. Robert Brandom. Philosophy Now. Acumen, Chesham, 2008.

Jeremy Wanderer. Brandom's challenges. In Bernhard Weiss and Jeremy Wanderer, editors, Reading Brandom: On Making it Explicit, pages 96-114. Routledge, London and New York, 2009.

Bernhard Weiss. What is logic? In Bernhard Weiss and Jeremy Wanderer, editors, Reading Brandom: On Making it Explicit, pages 247-261. Routledge, London and New York, 2009.

Adina Williams, Nikita Nangia, and Samuel R Bowman. A broad-coverage challenge corpus for sentence understanding through inference. arXiv preprint, 2017. URL https : / / arxiv . org / abs/1704.05426.

Timothy Williamson. Knowing and asserting. The Philosophical Review, 105(4):489-523, 1996.

Andrzej Wiśniewski. Questions, inferences, and scenarios. College Publications, 2013.

Andrzej Wiśniewski. Semantics of questions. In The Handbook of Contemporary Semantic Theory, 2nd Edition, pages 273-313. Wiley, 2015.

Ludwig Wittgenstein. Philosophical investigations, 4th edition. John Wiley \& Sons, 2009. 